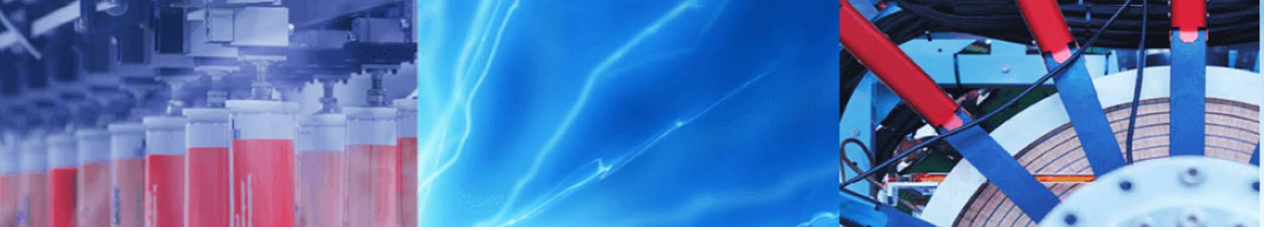

Research Article

\title{
Measurements and reanalysis data on wind speed and solar irradiation from energy generation perspectives at several locations in Poland
}

\author{
Adam Piasecki $^{1}$ (D) Jakub Jurasz ${ }^{2,3}$ (D) Alexander Kies $^{4}$ (D)
}

(C) The Author(s) 2019 OPEN

\begin{abstract}
Energy system research requires input data with high temporal and spatial resolution. However, the measurements performed in meteorological stations are only available for selected locations. Currently a growing number of research papers on small and large-scale power systems utilizes data coming from satellite measurements and various reanalyses. Although many authors aimed at comparing various data sources on irradiation and wind speed there is a lack of such studies, which compare both resources simultaneously at the same location. In consequence, many studies which are entirely based on satellite/reanalysis data may not be representative. In this paper 15 locations in Poland have been selected where the National Institute of Meteorology and Water Management performs continuous measurements of wind speed, temperature and global irradiation on a horizontal surface. Hourly time series were obtained for the year 2012 and 2013. The renewable resources were converted into electrical energy, considering the performance of typical PV panels and wind turbines. The findings of this study are as follows: solar radiation (CAMS and ERA5) shows a good agreement with ground measurements, for hourly values the coefficient of correlations is greater than 0.9 ; for individual locations the energy yield from PV system can differ by up to $9 \%$ but on average (all locations) the simulated energy yield based on satellite data is higher by less than $0.5 \%$; simulations for wind energy showed a large variability in results with differences in capacity factors reaching 15 percentage points.
\end{abstract}

Keywords Capacity factor - Variable renewable energy · Meteorological data · Power system simulation · ERA5 - MERRA

\section{Introduction}

Meteorological data is a crucial input in energy system models. Wind speed, irradiation and temperature are used to estimate the energy production from renewable generators like photovoltaics (PV) or wind turbines installed in a given location. Over recent years more and more attention is being paid the models focusing on large scale renewables based energy systems [1, 2]. The validity of results obtained by those models is most likely significantly affected by the quality of the input data. Since measurements are rarely available in a desired spatial density and therefore often inadequate for simulations (for example wind speed data is provided only at 10 meters above ground level, whereas a modern wind turbine has a hub height often exceeding 100 meters). In addition, ground measurements often tend to be incomplete (due to the equipment malfunction or closing of given measuring station). In such situations, data from satellite measurements and various reanalysis is applied. Such data is characterized by a relatively long temporal coverage (sufficient to consider in the modelling the inter-annual variability of wind and solar energy) and good spatial resolution and extend (available usually for the whole Earth).

$\triangle$ Adam Piasecki, adm.piasecki@gmail.com; Jakub Jurasz, jakubkamiljurasz@gmail.com; Jakub.jurasz@mdh.se; Alexander Kies, alexander.kies@gmail.com | ${ }^{1}$ Faculty of Earth Sciences, Nicolaus Copernicus University, Lwowska 1, 87-100 Toruń, Poland. ${ }^{2}$ Department of Engineering Management, Faculty of Management, AGH University, Gramatyka 10, 30-001 Cracow, Poland. ${ }^{3}$ School of Business, Society and Engineering, MDH University, Högskoleplan 1, 72220 Västerås, Sweden. ${ }^{4}$ Frankfurt Institute for Advanced Studies, Goethe University Frankfurt, 60438 Frankfurt am Main, Germany. 
Considering the common availability of satellite/reanalysis data it is not surprising that is being more and more often used in simulation models. However, the questions arise with regard to the quality of such data. Namely, if the satellite/reanalysis based time series of wind speed and irradiation exhibits the same qualities as ground measurements. Several research papers were dedicated to the use of such data sources in energy systems analysis. Andresen and et al., [3] presented an atlas for estimation of energy generation from renewable sources (wind and solar) and stressed the importance of using high quality data in energy system simulations. Olauson and Bergkvist [4] modelled the operation of Swedish wind parks based on MERRA data and found it quite well fitting the measured data. Pfenninger and Staffell [5] performed the comparison of measurements with satellite and reanalysis data for over 1000 locations in Western Europe. They found that neither of two sources is superior. Staffell and Pfenninger [6] used reanalysis data and found that its application requires a prior validation, however proper data preparation enables simulation of European wind sector with a good accurace $\left(R^{2}>0.95\right)$. Pfeifroth et al., [7] compared the trends and variability of surface solar radiation based on measurements and satellite data sources. Frank et al., [8] proposed new data sets, which outperform ERA-Interim and MERRA-2 thanks to the bias correction.

To the best of the Authors' knowledge, the satellite/reanalysis data has so far not been compared with the measurements provided by the National Institute of Meteorology and Water Management from the renewable energy sources perspective. Two studies by Jurasz et al., $[9,10]$ provide an anecdotal evidence that satellite/reanalysis data might be useful to simulate the polish wind energy sector and irradiation measurements, showing a good fit with satellite data. However, considering the growing importance of renewable energy sources in the Polish power system (despite some legislative upheavals), there is a pressing need to investigate if satellite/reanalysis based data is sufficient for simulation and optimization of the future energy system dominated by renewables. Considering above, the objective of this study is to compare the theoretical energy yield from a PV system and wind turbine situated in various locations in Poland. The analysis focuses on the energy yield per $\mathrm{kW}$ of installed capacity and variation in the capacity factor. The aim of this works is to answer the question, how big (if) are the differences between energy generation estimated based on various data sources.

\section{Data and methods}

For the purpose of this study data on solar radiation (global horizontal irradiation), temperature and wind speed has been downloaded from freely available sources. In total
15 locations in Poland were selected (see Fig. 1). Considered data covered years 2012 and 2013 and was available with an hourly time step. Table 1 summarizes data source and provides the necessary references. Overall, in case of each location energy generation from $\mathrm{PV}$ and wind turbine has been estimated based on three data sources. In case of two locations (Puławy and Lublin) only one renewable resources was considered due to lack of ground measurements (Puławy - no wind speed measurements, Lublin - no irradiation measurements).

To estimate the energy generated by a PV installation on an hourly basis, the following formulas were applied.

$E^{P V}=P^{P V} \frac{H}{H^{S T C}}\left[1-\mu\left(T^{C}-T^{S T C}\right)\right] \eta^{P V}$

$T^{C}=T_{a}+H\left(\frac{T^{N O C T}-20}{800}\right)$

where $E^{P V}$ energy generated by PV system [kWh], $P^{P V}$ installed capacity if PV system [kW], $H$ irradiation [kWh], $H^{S T C}$ irradiation in standard testing conditions $[\mathrm{kWh}], \mu$ temperature dependent efficiency reducing coefficient $[-], T^{C}$ operating temperature of PV modules $\left[{ }^{\circ} \mathrm{C}\right], T^{\text {STC }} \mathrm{PV}$ modules operation temperature in standard testing conditions $\left[{ }^{\circ} \mathrm{C}\right], \eta^{P V}$ overall efficiency of the PV system [\%], $T_{a}$ air temperature $\left[{ }^{\circ} \mathrm{C}\right], T^{\mathrm{NOCT}}$ temperature in normal operating conditions $\left[{ }^{\circ} \mathrm{C}\right]$.

The energy available from given wind speed at certain height can be either estimated based on general formulas or by considering a power curve of a wind turbine available on the market. Here, the second approach has been selected [11] and a common Vestas V90 (Fig. 2) wind turbine was considered. Prior to estimating the energy generation from wind turbine the wind speed has been recalculated from 10 meters above ground level to the hub height of 100 meters above ground level. For that purpose, a power low was used with an exponent equal to 1/7. Later, Eq. 3 can be directly applied to calculate the energy yield from wind turbine.

$P=\left\{\begin{array}{l}0 \quad \text { for } v \in 0, v_{\text {cut-in }} \cup\left\langle v_{\text {cut-off }},+\infty\right\rangle \\ P(v) \text { for } v \in\left(v_{\text {cut-in }}, v_{\text {rated }}\right) \\ P_{\text {max }} \text { otherwise }\end{array}\right.$

where $P$ power generated by wind turbine $[\mathrm{kW}], v$ wind speed $[\mathrm{m} / \mathrm{s}], v_{\text {cut-in }}$ cut-in wind speed $[\mathrm{m} / \mathrm{s}], v_{\text {rated }}$ rated wind speed $[\mathrm{m} / \mathrm{s}], v_{\text {cut-off }}$ cut-off wind speed [m/s], $P(v)$ polynomial describing power output as function of wind speed $[\mathrm{kW}], P_{\max }$ maximal power of wind turbine $[\mathrm{kW}]$. 
Fig. 1 Location of selected sites. Full circle-both wind and irradiation data were available, black/white circle-only irradiation data, white/blackonly wind data
Table 1 Summary of data sources used

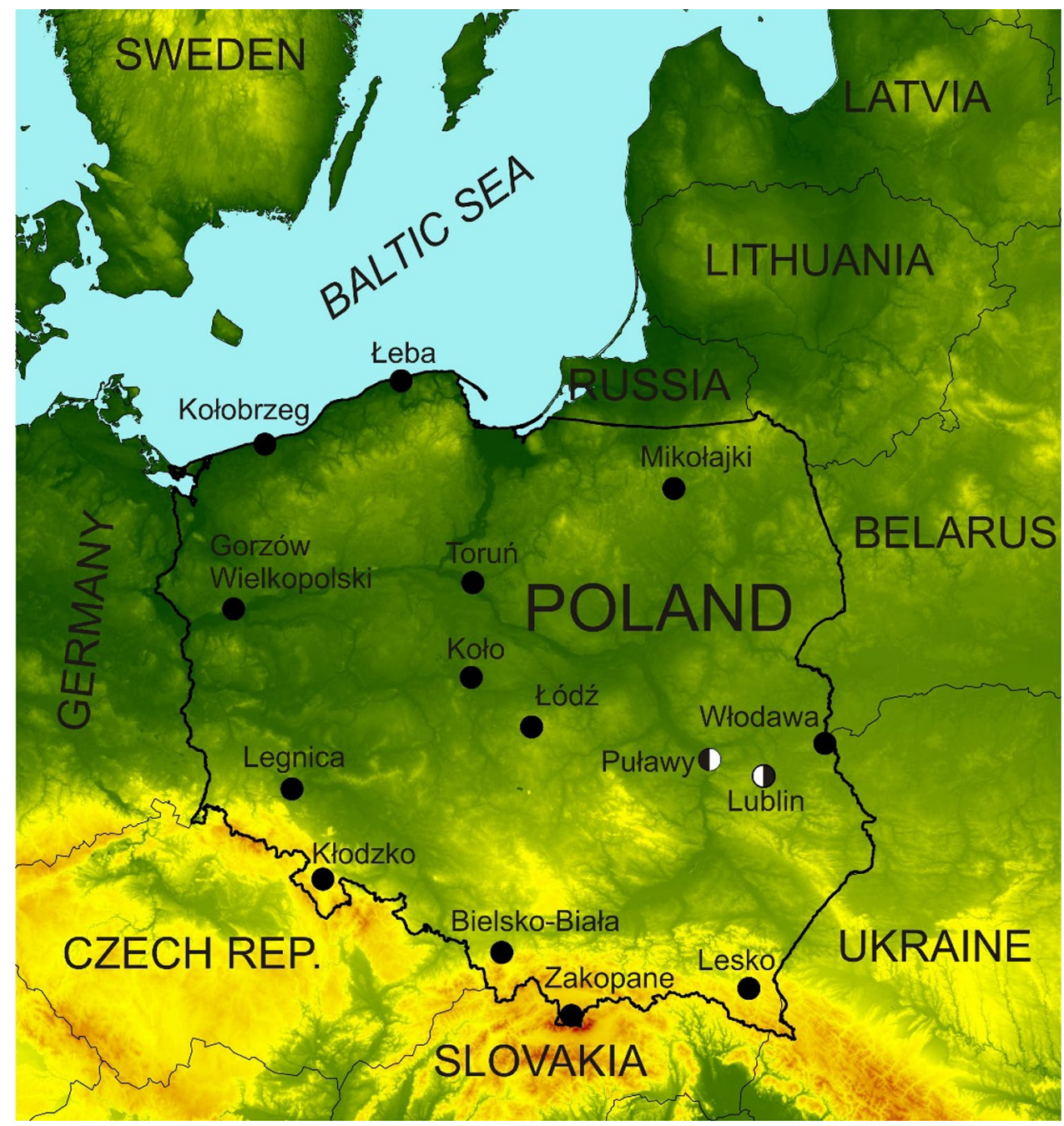

\begin{tabular}{lll}
\hline Source & References & Meteorological parameter provided \\
\hline IMGW PIG & https://danepubliczne.imgw.pl/ & Wind speed, temperature, irradiation \\
CAMS & http://www.soda-pro.com/ & Irradiation \\
MERRA & https://gmao.gsfc.nasa.gov & Wind speed, temperature \\
ERA5 & https://cds.climate.copernicus.eu & Irradiation, wind speed, temperature
\end{tabular}

\section{Results and discussion}

It can be assumed that the ground measurements of irradiation are representative and may translate directly into the energy yield of optimally designed PV systems in given location or even larger area. However, the nature of wind energy is much more volatile and differ significantly from location to location. Historically, the meteorological stations measuring wind speed were located on the city outskirts. Yet, the continuous urbanization lead to drastic changes in their localization. Some of them are currently located within the cities and are surrounded by dense and high development. This in consequence has an impact on the local climate (including wind speed).

The disturbance of wind speed within cities as a result of significant surface roughness has already been well documented. In the literature, the wind speed is reduced by $20-30 \%$ in urban development in relation to the peripheral areas of cities [12,13]. In city centers characterized by the densest buildings, the mentioned speed drop reaches $50 \%[14,15]$. The consequence of the reduced wind speed in cities is the more frequent occurrence of atmospheric silence. It is a phenomenon 
Fig. 2 Vestas V90 power curve for wind speeds from 3.5 to $12 \mathrm{~m} / \mathrm{s}$

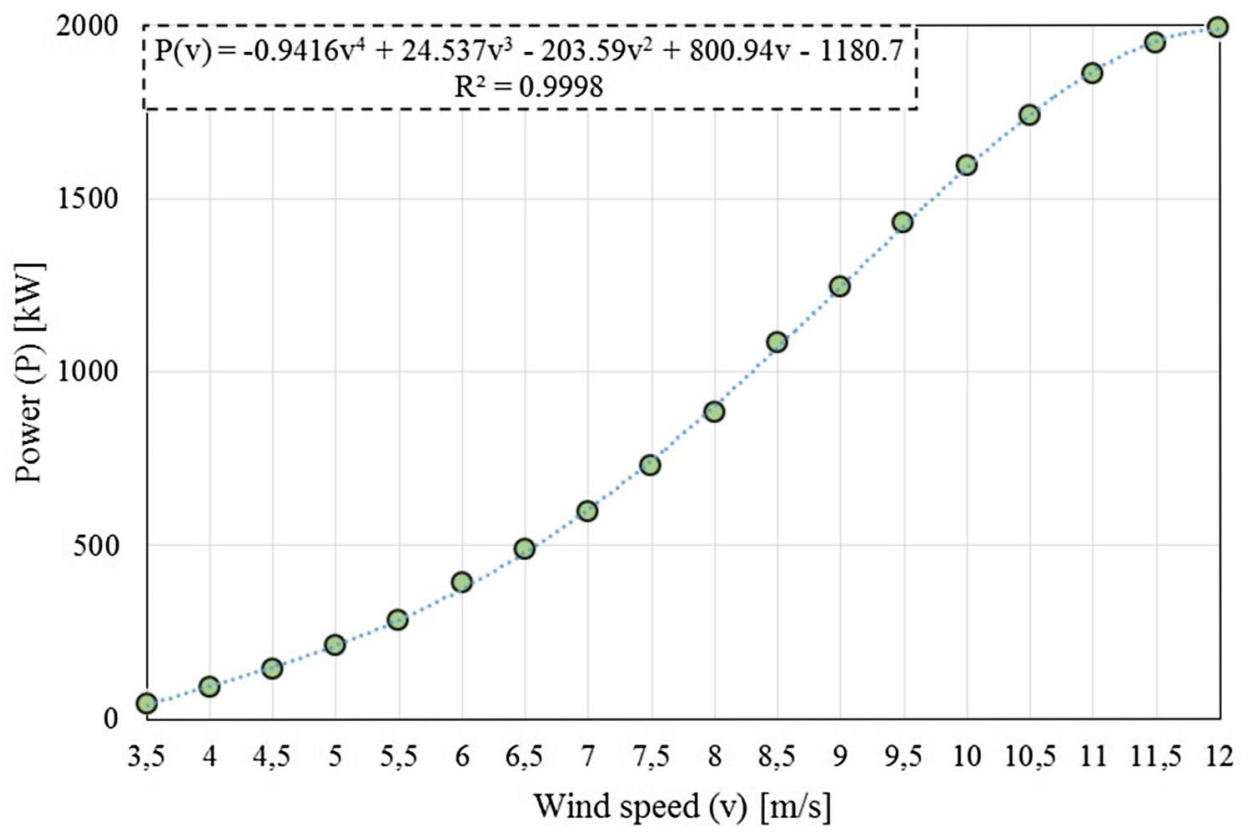

very burdensome for urban residents, because it intensifies problems related to the accumulation of pollutants and the removal of heated air [16]. It affects the occurrence, intensity, and vertical range of the urban heat island $[17,18]$.

It must be noted that large-scale wind projects are usually located in areas located far away from human settlements; therefore, comparison of wind potential in cities has a limited applicability. Unfortunately, measurements from commercial masts (located in wind parks or other prospective locations) are not available.

First part of our work focuses on calculating the energy yield from PV and wind turbine systems located in each selected location. Further, the respective energy yields are used to estimate the energy source capacity factor. Capacity factor is a representative metric which is defined as a sum of energy delivered over 1 year divided by the theoretical energy generation if the generator worked under full load for the whole year. Here, 2 years of data were used to calculate the capacity factor twice and later average it. The results of our calculations are presented on Figs. 3 and 4. Firstly, one can observe that the estimations for wind turbine exhibit a much higher variability than for PV system. It is in line with the current knowledge that the potential of solar energy in Poland is rather uniform, whereas wind energy exhibits significant variation. Secondly, the estimations for wind generation can be off by as much as 30 percentage points (for example Kołobrzeg where ground measurements indicate capacity factor of $15 \%$ and MERRA data of close to $45 \%$ ). Thirdly, the estimations for solar energy based on MERRA and ERA5 data show a good match with ground measurements. The highest observed difference amounts to 0.9 percentage points and was observed for Łódź.

From values presented in Fig. 3, we can observe that, in general, MERRA tends to overestimate the energy generation from wind turbines in comparison to ERA5 and ground measurements. The average capacity factor for wind turbine for all locations based on those data sources was respectively: $15.9 \%, 26.4 \%$ and $15.8 \%$. The low value of capacity factor for ground measurements can be attributed to the fact that meteorological stations are situated in locations which are from practical point of view not suitable for wind projects development. At this point it is worth to add that considering the energy production from wind sources in Poland over the year 2017 [19], which amounted to $14.909 \mathrm{TWh}$, and assuming the installed capacity to be equal to $5.858 \mathrm{GW}$, the average capacity factor of polish wind parks was $29.1 \%$. This indicates that the wind energy conditions are much better in Poland in the areas different than those covered by the selected meteorological stations. Or the locations of stations, especially the wind speed meter does not reflect the wind conditions over larger areas. Also the capacity factor of wind turbines increases with the hub height.

The same analysis has been performed for the PV generation. As can be observed in, Fig. 4 there are locations for which all data sources indicate the same value of the capacity factor (Puławy) or where two sources have relatively similar values, whereas the third is significantly different (Włodawa). Interestingly, good match can be observed between measurements and CAMS (Gorzow Wielkopolski) and lower values are calculated based on ERA5. In the same time in Włodawa CAMS and ERA5 have 


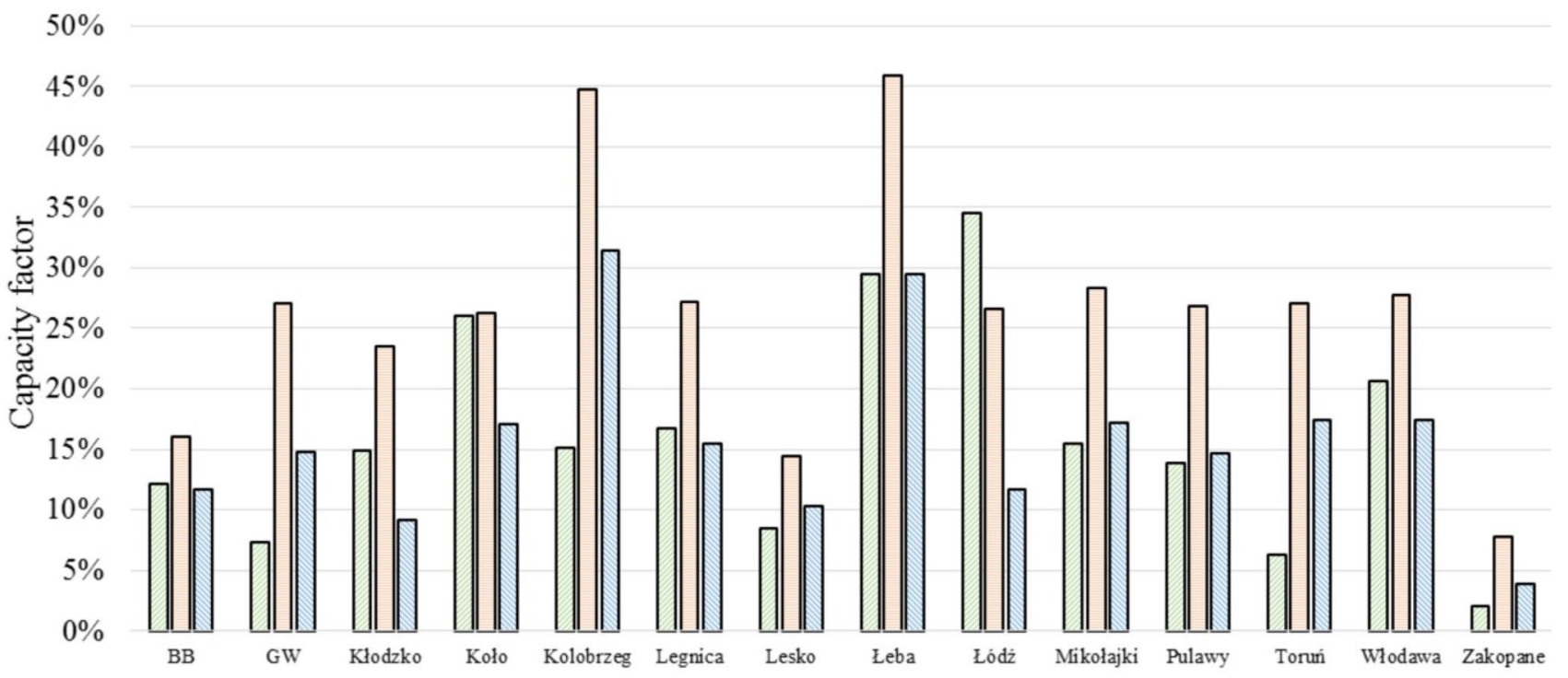

口Ground measurements $\quad$ QReanalysis_MERRA $\quad$ Reanalysis_ERA5

Fig. 3 Theoretical capacity factors for Vestas V90 wind turbine

$12.0 \%$

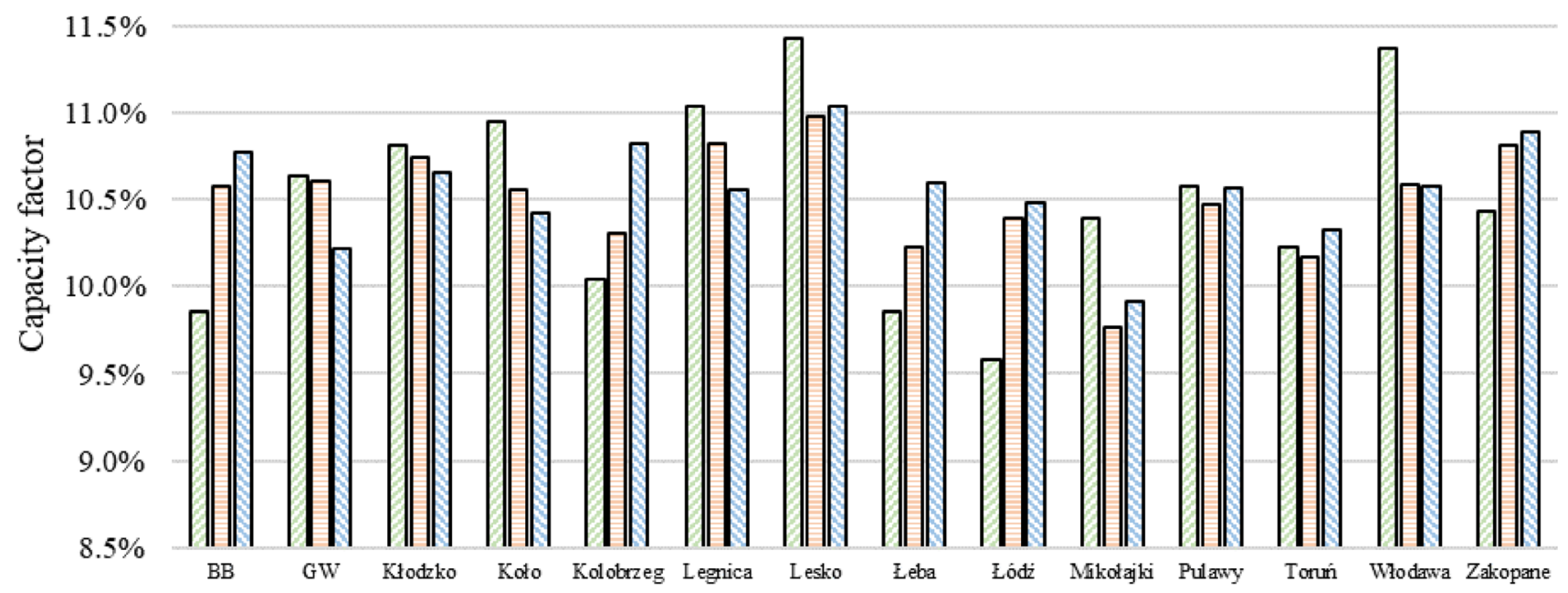

口Ground measurements $\square$ Satellite_CAMS QReanalysis_ERA5

Fig. 4 Theoretical capacity factors for PV systems

good match whereas ground measurements have much higher value (more by almost $0.8 \%$ point). Taking into the consideration the average values calculated for the whole Poland it was found that for a representative PV system the energy yield should be $921 \mathrm{kWh}, 920 \mathrm{kWh}$ and $925 \mathrm{kWh}$ for, respectively, ground measurements, CAMS and ERA5.
For the location Koło we have also compared the hourly generation values. Figure 5 presents scatter plots for all possible combinations of data sources. The highest value of the coefficient of correlation was observed between ground measurements and CAMS (0.966), second came CAMS and ERA5 (0.954) and the lowest between ground measurements and ERA-5. 

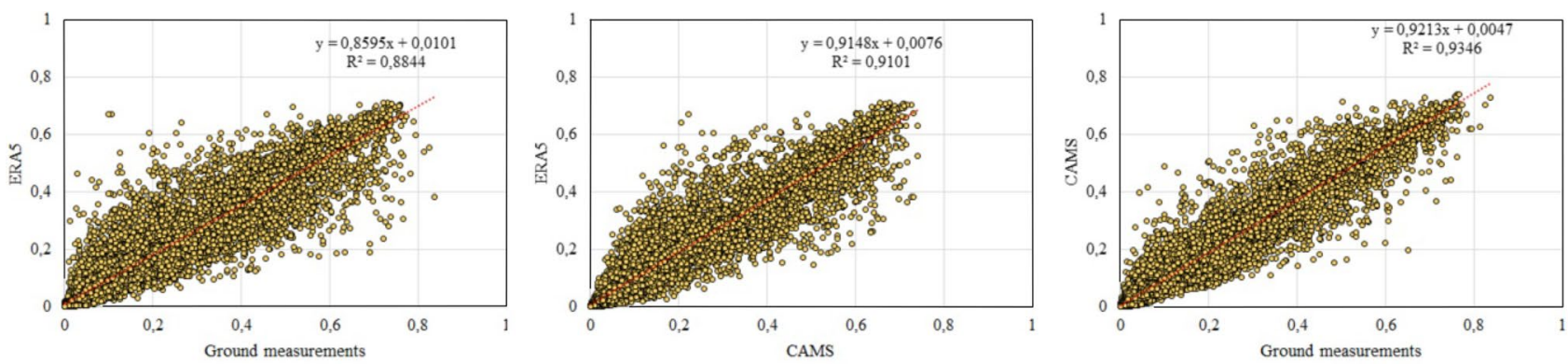

Fig. 5 Comparison of hourly PV energy generation between different data sources for location: Koło

If the energy generation match is assessed based on a daily time scale, the following (for measurements-CAMS, measurements-ERA5) can be observed (see Fig. 6). In terms of energy the maximal overestimation in case of ERA data source amounted to $2.5 \mathrm{kWh}$, whereas in case of CAMS data to $1.8 \mathrm{kWh}$ (this values refer to a PV system with a capacity of $1 \mathrm{~kW}$ ). When mismatch values are compared to the daily energy generation (based on ground measurements), values as high as $200 \%$ (overestimation) and $50 \%$ (underestimation) can be observed. An overestimation by $100 \%$ means that the PV system theoretically generated 4 $k W h$ of electrical energy (based on ground measurements) on a daily basis, whereas other data sources indicated an energy yield of $8 \mathrm{kWh}$.

The final part of the analysis is dedicated to the mean monthly values of hourly energy generation from a wind turbine. Again, location Koło has been selected for more detailed analysis. On Fig. 7 we have presented the outcome of our calculations. As can be observed, the data sources follow the same annual patterns. Namely, the lower generation values are observed in the middle of the year, whereas the energy generation from the wind turbine increases in Autumn-Winter period. In case of all months, the ground measurements and MERRA show a good fit. However, the ERA5 suggested significantly lower values (often by more than $200 \mathrm{kWh}$ - which is equal to $10 \%$ of the turbine nominal capacity). As indicate by [20] this difference could be attributed to the fact that reanalysis data is characterized by a good fit with measurements on open areas, whereas in mountainous regions, where often local wind regimes are dominant, it (the reanalysis data) cannot provide a good fit with measurements.
Fig. 6 Mismatch between daily energy generation estimated based on ground measurements and CAMS and ERA5 data. Negative values indicate situation when the energy yield based on ERA5 or CAMS was higher than that estimate based on ground measurements

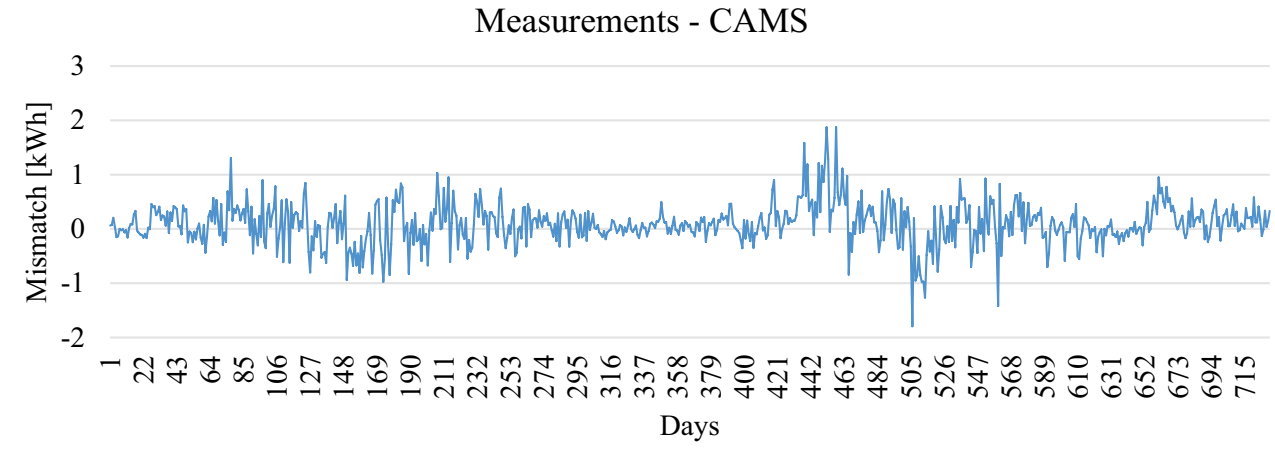

Measurements - ERA-5

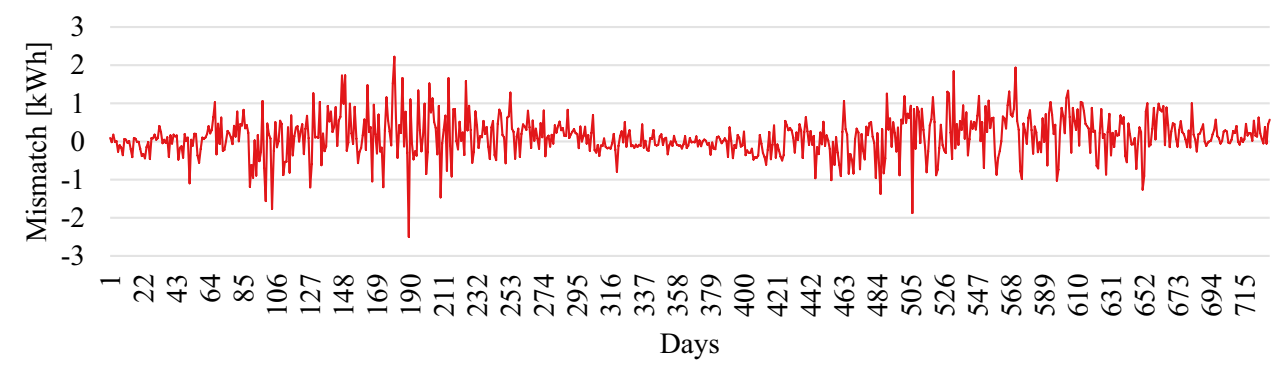

SN Applied Sciences 


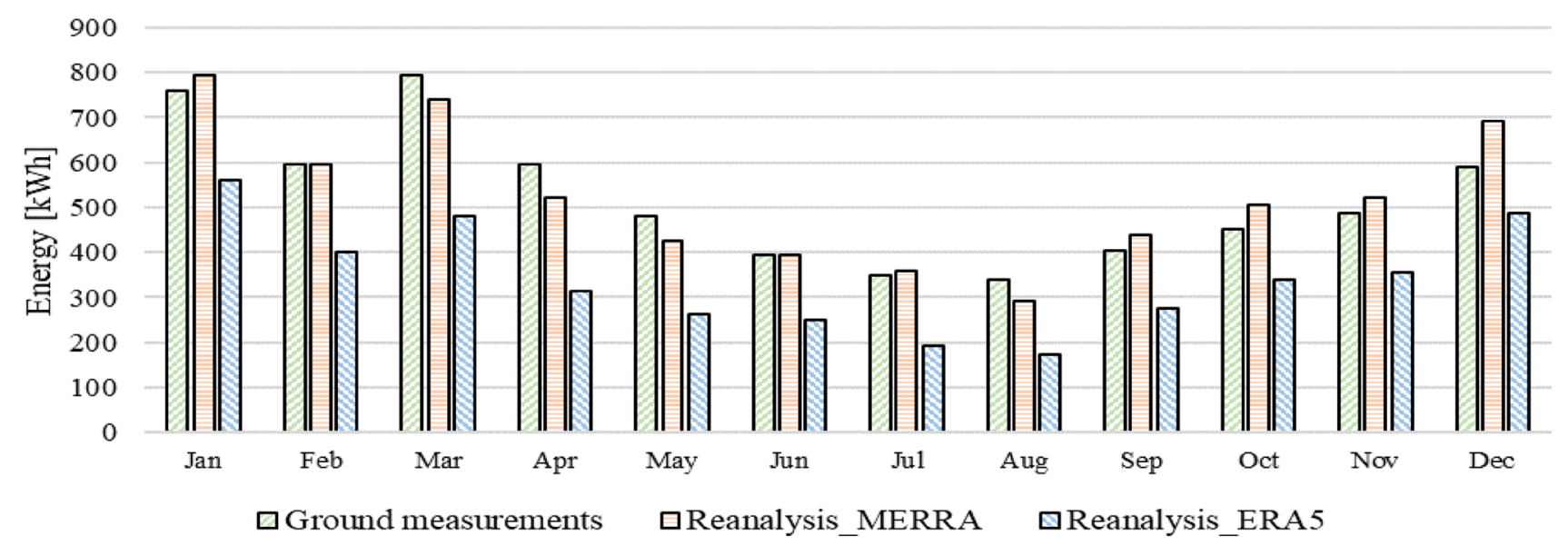

Fig. 7 Mean hourly energy generation from Vestas V90 wind turbin in location: Koło

\section{Conclusions}

This research paper presents results of an analysis aiming at assessing how good is the representation of wind speed and irradiation meteorological parameters obtained from satellite and reanalysis in comparison to ground measurements. The analysis was conducted from the energetic point of view by converting the irradiation and wind speed into useful electrical energy considering the typical generators performance. Overall, both CAMS and ERA5 datasets have shown a good fit with the ground measurements for solar energy. The average estimated energy yield per $1 \mathrm{~kW}$ of installed capacity in PV was almost the same for all sources and the differences were less than $1 \%$. The wind speed is a phenomena with a much more variable characteristic on a spatial scale and therefore the fit between ground measurements and reanalysis data (MERRA and ERA5), which are rather spatially coarse, was relatively poor. Only for two locations (Koło and Łeba), the reanalysis datasets showed a very good match with ground measurements. In our opinion, and based on the conducted analysis, both CAMS and ERA5 are suitable for estimation of energy yield from PV installation in Poland. However, those estimates should be treated with caution, as on the hourly basis the differences between individual data sources can be significant. If real load data will be compared with the energy yield estimated based on CAMS or ERA5, theoretically errors may occur due to the fact that the electrical load to some extent is influenced by the irradiation.

This study answered some of the questions regarding the applicability of the satellite/reanalysis data in renewable energy sources simulation in Poland. However, the overwhelming part of questions remains unanswered. Therefore, in future research we emphasize to focus on the following: detailed analysis of how datasets match on an hourly basis and application of the data to the models of renewable-based energy systems in Poland.

In addition, we would like to apply more sophisticated wind potential methods, which has been successfully applied by, inter alia [21, 22].

Funding This study was funded from own resources.

\section{Compliance with ethical standards}

Conflict of interest The authors declare that they have no conflict of interest.

Open Access This article is distributed under the terms of the Creative Commons Attribution 4.0 International License (http://creativecommons.org/licenses/by/4.0/), which permits unrestricted use, distribution, and reproduction in any medium, provided you give appropriate credit to the original author(s) and the source, provide a link to the Creative Commons license, and indicate if changes were made.

\section{References}

1. Jurasz J, Dąbek PB, Kaźmierczak B, Kies A, Wdowikowski M (2018) Large scale complementary solar and wind energy sources coupled with pumped-storage hydroelectricity for Lower Silesia (Poland). Energy 161:183-192. https://doi.org/10.1016/j.energ y.2018.07.085

2. Schlott M, Kies A, Brown T, Schramm S, Greiner M (2018) The impact of climate change on a cost-optimal highly renewable European electricity network. Appl Energy 230:1645-1659. https://doi.org/10.1016/j.apenergy.2018.09.084

3. Andresen GB, Søndergaard AA, Greiner M (2015) Validation of Danish wind time series from a new global renewable energy atlas for energy system analysis. Energy 93:1074-1088. https:// doi.org/10.1016/j.energy.2015.09.071

4. Olauson J, Bergkvist M (2015) Modelling the Swedish wind power production using MERRA reanalysis data. Renew Energy 76:717-725. https://doi.org/10.1016/j.renene.2014.11.085 
5. Pfenninger S, Staffell I (2016) Long-term patterns of European PV output using 30 years of validated hourly reanalysis and satellite data. Energy 114:1251-1265. https://doi.org/10.1016/j.energ y.2016.08.060

6. Staffell I, Pfenninger S (2016) Using bias-corrected reanalysis to simulate current and future wind power output. Energy 114:1224-1239. https://doi.org/10.1016/j.energy.2016.08.068

7. Pfeifroth U, Sanchez-Lorenzo A, Manara V, Trentmann J, HolImann R (2018) Trends and variability of surface solar radiation in Europe based on surface-and satellite-based data records. J Geophys Res Atmos 123(3):1735-1754. https://doi. org/10.1002/2017JD027418

8. Frank CW, Wahl S, Keller JD, Pospichal B, Hense A, Crewell S (2018) Bias correction of a novel European reanalysis data set for solar energy applications. Sol Energy 164:12-24. https://doi. org/10.1016/j.solener.2018.02.012

9. Jurasz J, Wdowikowski M, Kaźmierczak B, Dąbek P (2017) Temporal and spatial complementarity of wind and solar resources in Lower Silesia (Poland). In: E3S web of conferences, vol 22, p 00074, EDP Sciences. https://doi.org/10.1051/e3sconf/20172 200074

10. Jurasz J, Mikulik J, Ciapała B (2018b) Potential extreme events in the Polish wind energy sector, based on historical data. In: E3S web of conferences, vol 44, p 00059, EDP Sciences. https://doi. org/10.1051/e3sconf/20184400059

11. Lydia M, Kumar SS, Selvakumar Al, Kumar GEP (2014) A comprehensive review on wind turbine power curve modeling techniques. Renew Sustain Energy Rev 30:452-460. https://doi. org/10.1016/j.rser.2013.10.030

12. Klaić ZB, Nitis T, Kos I, Moussiopoulos N (2002) Modification of the local winds due to hypothetical urbanization of the Zagreb surroundings. Meteorol Atmos Phys 79(1-2):1-12. https://doi. org/10.1007/s703-002-8225-z

13. Fortuniak K, Kłysik K, Wibig J (2006) Urban-rural contrasts of meteorological parameters in Łódź. Theoret Appl Climatol 84(1-3):91-101. https://doi.org/10.1007/s00704-005-0147-y

14. Nidzgorska-Lencewicz J, Czarnecka M (2011) Deformation of the anemometric conditions in Szczecin. Prace i Studia Geograficzne 47:401-408
15. Grawe $D$, Thompson HL, Salmond JA, Cai XM, Schlünzen $K H$ (2013) Modelling the impact of urbanisation on regional climate in the Greater London Area. Int J Climatol 33(10):2388-2401. https://doi.org/10.1002/joc.3589

16. Klemm K (2011) The influence of changes in buildings configuration on air flow. Fizyka Budowli w Teorii i Praktyce 6:53-58

17. Morris CJG, Simmonds I, Plummer N (2001) Quantification of the influences of wind and cloud on the nocturnal urban heat island of a large city. J Appl Meteorol 40(2):169-182. https ://doi.org/10.1175/1520-0450(2001)040\%3C0169:QOTIO W\%3E2.0.CO;2

18. Kassomenos PA, Katsoulis BD (2006) Mesoscale and macroscale aspects of the morning urban heat island around Athens, Greece. Meteorol Atmos Phys 94(1-4):209-218

19. Gospodarka paliwowo-energetyczna w latach 2016 i 2017 (pol.). Główny Urząd Statystyczny, 2018-11-09. s. III_Bilanse przemiany energii.xls tabl. 14(19). http://stat.gov.pl/obszary-tematyczne/ srodowisko-energia/energia/gospodarka-paliwowo-energetycz na-w-latach-2016-i-2017,4,13.html. Accessed 9 Nov 2018

20. John J, Ramírez C (2015) MERRA-based study of the wind/solar resources and their complementarity to the hydro resource for power generation in Colombia. Carl von Ossietzky Universität Oldenburg, Master-Arbeit

21. Vanvyve E, Delle Monache L, Monaghan AJ, Pinto JO (2015) Wind resource estimates with an analog ensemble approach. Renew Energy 74:761-773. https://doi.org/10.1016/j.renen e.2014.08.060

22. González-Aparicio I, Monforti F, Volker P, Zucker A, Careri F, Huld T, Badger J (2017) Simulating European wind power generation applying statistical downscaling to reanalysis data. Appl Energy 199:155-168. https://doi.org/10.1016/j.apenergy.2017.04.066

Publisher's Note Springer Nature remains neutral with regard to jurisdictional claims in published maps and institutional affiliations. 